\title{
Cesarean Section and Associated Factors at Aira Hospital, Oromia Region, Western Ethiopia: A Retrospective Record Review
}

\author{
Keressa Duressa ${ }^{1}$, Gelana Fekadu ${ }^{2,}$,, Bedasa Taye ${ }^{3}$, Henock Asfaw ${ }^{2}$ \\ ${ }^{1}$ West Wollega Zone, Aira Hospital, Oromia Region, Ethiopia \\ ${ }^{2}$ School of Nursing and Midwifery, College of Health and Medical Science, Haramaya University, Harar, Ethiopia \\ ${ }^{3}$ School of Public Health, College of Health and Medical Science, Haramaya University, Harar, Ethiopia
}

Email address:

dkeressa@gmail.com (K. Duressa), fekadugelana4@gmail.com (G. Fekadu), tbadhaasaa@gmail.com (B. Taye),

yaredasfaw33@gmail.com (H. Asfaw)

${ }^{*}$ Corresponding author

\section{To cite this article:}

Keressa Duressa, Gelana Fekadu, Bedasa Taye, Henock Asfaw. Cesarean Section and Associated Factors at Aira Hospital, Oromia Region, Western Ethiopia: A Retrospective Record Review. International Journal of Biomedical Engineering and Clinical Science.

Vol. 6, No. 1, 2020, pp. 1-6. doi: 10.11648/j.ijbecs.20200601.11

Received: January 26, 2020; Accepted: March 9, 2020; Published: April 8, 2020

\begin{abstract}
Introduction: According to the latest data from 150 countries, currently, $18.6 \%$ of all births occur by cesarean section, ranging from $6 \%$ to $27.2 \%$. It is alarmingly increasing in the last decade with an average annual rate of increase by 4.4\%. Objective: To assess the prevalence of the cesarean section and associated factors among mothers who gave a birth from January 01, 2014, to December 31, 2018, at Aira Hospital, west wollega zone, Oromia region, Ethiopia. Methods and materials: Study was conducted from June 1 to July 25, 2019, by retrospective review of complete medical records of mothers who gave birth from January 01, 2014, to December 31, 2018 at Aira general hospital, west wollega zone, Oromia region, Ethiopia. The sample size was determined by using single population proportion and the final sample size was 339 . Check list was used for data collection which was adapted and developed by reviewing relevant literatures. The data was analyzed by statistical package for social science version 20. Odd ratio was used for the interpretation of strength of prediction of independent variable to outcome variable, cesarean section. The statistical significance was declared at $\mathrm{P}<0.05$ with 95\% confidence interval. Result: A total of 332 medical records were reviewed. More than half $(51.8 \%)$ of mother were less than or equal to 24 years with the mean age of $24.23( \pm 5.17 \mathrm{SD})$. The prevalence of cesarean section was $33.1 \%$ (95\%CI 31.3-35.2\%). More than two third (85.5\%) of mothers had antenatal care follow up and the gestational age at the time of delivery was $37-40$ weeks for $90.7 \%$ of mothers. Maternal age, gestational age and fetal weight were factors associated with cesarean section. Conclusion: Since the current prevalence of cesarean section surpass the world health organization recommendation threshold vaginal delivery should be encouraged in appropriate cases and the time should be given for conservative management of fetal distress. Maternal age, gestational age and fetal weight were factors associated with cesarean section. We recommend a future researchers to examine the attitude of service providers and their influence on the growing cesarean section delivery rate.
\end{abstract}

Keywords: Cesarean Section, Associated Factors, Retrospective Record Review, Ethiopia

\section{Introduction}

The cesarean section (CS) is a lifesaving surgical procedure to prevent or treat life-threatening maternal or perinatal complications, and the appropriate rate should be associated with the lowest attainable maternal and perinatal morbidity and mortality [1, 2]. The medically indicative cesarean section is effective in reducing hurdles related to delivery and birth. However, since cesarean birth has risks of surgery and it increases the possibilities of complications in future pregnancies and might harm mothers and babies [3-5].

The complications may be developed intraoperative, 
postoperatively and on future pregnancy due to previous the cesarean section. The common adverse sequel of cesarean section includes blood loss, wound infection, uterine rupture, hematoma, cystitis, injury to organ, placenta accreta, anesthesia complications and re-operation [3, 4, 6]. It has also a negative influence on early initiation of breastfeeding [5] and associated with an increase in subsequent risk of asthma and childhood-onset type one diabetes [3].

In 1994, world health organization (WHO) published revised guidelines stating that cesarean birth rates should range between 5 and 15 percent, adding that rates lower than five percent reflect women's lack of access to life-saving care [7]. According to the latest data from 150 countries, currently, $18.6 \%$ of all births occur by cesarean section, ranging from $6 \%$ to $27.2 \%$ and it is alarmingly increasing in the last decade with an average annual rate of increase of $4.4 \%$ [8]. The WHO yielded an estimate of CS prevalence by continent; 36\% in America, 23\% in Europe, 9\% in Asia and $4 \%$ in Africa [9], while the study report from sub-Saharan African countries indicated $4.1 \%$ to $16.8 \%$ of cesarean section $[10,11]$.

The average national cesarean section prevalence in Ethiopia shows an increased trend with a prevalence of $0.7 \%$ in 2000 to $1.9 \%$ in 2016 [12]. The rate is substantially variable across administrative regions and places of delivery. For instance, Addis Ababa has the highest rate of the cesarean section, $21.4 \%$ in 2016 which surpassed the WHO recommendation and the greatest increase since 2000 (7.9\%). Conversely, low rate of the cesarean sections were noted in Somali (0.4\%), Afar (0.7\%), Oromia (0.9\%), Southern nation nationalities and peoples of Ethiopia (1.2\%), Gambela (1.3\%), Tigray (2.0\%), Benishangul-Gumuz (2.0\%), and Amhara (2.3\%) regions of Ethiopia. Cesarean birth in private health facilities increased from $6.7 \%$ in 2000 to $23.0 \%$ in 2016 while the rate in public health facilities decreased by $7.9 \%$ (from $14.4 \%$ in 2000 to $6.5 \%$ in 2016 ) [13].

Many factors have been claimed to be attributed for the increment of the cesarean section. While some literature reported socio-demographic factors to contribute for CS were maternal age, higher educational status, richest family and rural residence $[14,15]$, whereas obstetric factors include, cephalo-pelvic disproportion, obstructed labor, fetal distress, abnormal presentation, multiple pregnancies, multiple parity, fetal microsomia, previous CS, uterine rupture, antepartum hemorrhage, gestational age are factors contribute for cesarean section $[10,13,14,16-19]$. The place of delivery also another factor associated with it. Mothers who gave birth at private health facilities are more likely to undergo CS than who gave birth at public health facilities [11, 20, 21].

$A$ raise in a rate of $C S$ are not only determined by the maternal factors. However, factors related to the facility include, the capacity of the health system to deliver surgical obstetric care, its financing structure, and human resources profile, have stronger aggregate-level effects on cesarean section rates than does income [22]. However given only few studies are conducted in assessing the rate of the cesarean section in Ethiopia, perhaps in the oromia region [16, 17, 21].
Therefore, this study is aimed to assess the prevalence of cesarean section and associated factors at Aira General Hospital, Oromia region, western Ethiopia.

\section{Method and Materials}

\subsection{Study Setting and Period}

The study was conducted at Aira Hospital which is located in Aira District, West Wollega Zone of Oromia Region, at a distance of $520 \mathrm{~km}$ from the capital city, Addis Ababa. Aira hospital is a general Hospital rendering a service to an estimated 300,000 people. The study was conducted from June 1, to July 25, 2019.

\subsection{Study Design and Population}

A retrospective medical record review was conducted among women who gave birth in Aira hospital in the last five years, from January 01,2014 , to December 31, 2018, were included, while the medical record of mothers with incomplete information was excluded.

\subsection{Sample Size and Sampling Procedure}

Sample size was determined using the formula for single population proportion by considering the prevalence of cesarean section $27.6 \%$ [18], 95\% level of confidence, $5 \%$ margin of error and $10 \%$ none response rate was added and yielded a final sample size of 339. Systematic random sampling technique was used to select the study participants by using the delivery registration book as sampling frame. The interval " $k$ " was used to select the study participant from the sample frame. Accordingly, the total number of deliveries during the last five year period were 2,737 deliveries. By dividing the total number of deliveries for the final sample size, $k=8(2,737 / 339)$. So every $8^{\text {th }}$ woman from the sampling frame was included.

\subsection{Data Collection Procedure and Tools}

The data was collected by reviewing the medical record of mothers. Two data collectors (BSc nurses) and one supervisor (MSc Nurse) were participated on data collection. The checklist was developed and adapted by reviewing relevant literatures $[13,16-18,21,23-25]$. Variables included in checklist form were maternal age, residence, gravidity, gestational age at delivery in weeks, ANC follow up, fetal weight, mode of delivery, indication for the cesarean section, fetal outcome, frequency and type of caesarean section.

\subsection{Data Quality Assurance}

In order to maintain quality of the data, training was given for data collectors and supervisors on data collection procedures. Daily follow-up was made by supervisors to ensure the quality of data collection process and feedback was given for data collectors accordingly. Before the commencement of data collection the tool was pretested with 
$5 \%$ of sample size in Gimbi adventist hospital which found $60 \mathrm{~km}$ away from the study area and possible modifications were made on the tool. Completeness of data were checked daily and coded before the data analysis.

\subsection{Data Processing and Analyses}

Data were entered to Epi info version 3 and statistical packages for social sciences (SPSS) version 20 was used for analysis. Bivariate and multivariable logistic regression analysis was computed. Those variables with P-value of less than or equal to 0.2 were taken to multivariable logistic regression. The independent effect of each variable on the outcome variable was seen with to multivariable logistic regression and it were presented in crude and adjusted odds ratio (OR) with their corresponding 95\% confidence intervals. The statistical significance was declared at $\mathrm{P}<0.05$.

\section{Results}

\subsection{Socio Demographic Characteristics}

Ninety-eight percent of the sampled medical records of mothers were reviewed. The mean age of the participants was $24.23( \pm 5.17 \mathrm{SD})$ with a range of $15-42$ years and more than half $(51.8 \%)$ of mother were less than or equal to 24 years, followed by mothers whose age group 25-34 (43.7\%). Concerning their residence more than half $(58.7 \%)$ were from rural areas (table 1).

Table 1. Socio-demographic characteristics of mothers who gave a birth from January 01, 2014, to December 31, 2018, at Aira Hospital, west wollega zone, Oromia Region, Ethiopia. July 2019, $n=332$.

\begin{tabular}{lll}
\hline Characteristics & Frequency & Percentage (\%) \\
\hline Age & & \\
$<=24$ & 172 & 51.8 \\
$25-34$ & 145 & 43.7 \\
$>=35$ & 15 & 4.5 \\
Residence & & \\
Urban & 137 & 41.3 \\
Rural & 195 & 58.7 \\
\hline
\end{tabular}

\subsection{Prevalence of the Cesarean Section and Obstetric Characteristics of Mothers}

The current prevalence of the cesarean section was $33.1 \%$ (95\%CI 31.3-35.2\%). Two hundred (60.2\%) of the mothers were multigravidas, while all of the mothers were in the third trimester during their delivery. Less than one-third (29.2\%) had previous abortions and only $(20.5 \%)$ had history of still births in the previous pregnancies. More than two-third (85.5\%) of mothers had ANC follow up and the gestational age at the time of delivery was $37-40$ weeks for $90.7 \%$ of mothers. Fifty-two (15.6\%) of mothers had previous history of the cesarean section, among them $61.5 \%$ of them had once. Regarding the indication of the cesarean section majority $33.6 \%$ were previous history of cesarean section, followed by NRFHR (Table 2).
Table 2. The cesarean section and obstetric characteristics of mothers who gave a birth from January 01, 2014, to December 31, 2018, at Aira Hospital, west wollega zone, Oromia Region, Ethiopia. July 2019, $n=332$.

\begin{tabular}{|c|c|c|}
\hline Obstetric History & Frequency & Percentage (\%) \\
\hline \multicolumn{3}{|l|}{ Gravida } \\
\hline 1 & 91 & 27.5 \\
\hline $2-4$ & 200 & 60.2 \\
\hline$\geq 5$ & 41 & 12.3 \\
\hline \multicolumn{3}{|l|}{ Previous still births } \\
\hline Yes & 68 & 20.5 \\
\hline No & 264 & 79.5 \\
\hline \multicolumn{3}{|l|}{ Abortions } \\
\hline Yes & 97 & 29.2 \\
\hline No & 235 & 70.8 \\
\hline \multicolumn{3}{|c|}{ Number of abortions $(n=97)$} \\
\hline 1 & 58 & 59.8 \\
\hline$\geq 2$ & 39 & 40.2 \\
\hline \multicolumn{3}{|l|}{ ANC Follow-up } \\
\hline Yes & 284 & 85.5 \\
\hline No & 48 & 14.5 \\
\hline \multicolumn{3}{|l|}{ Gestational age } \\
\hline 37 - 40 weeks & 301 & 90.7 \\
\hline$>40$ weeks & 31 & 9.3 \\
\hline \multicolumn{3}{|c|}{ Number of previous CS $(n=52)$} \\
\hline One & 32 & 61.5 \\
\hline Two & 20 & 38.5 \\
\hline \multicolumn{3}{|l|}{ Current CS } \\
\hline Yes & 110 & 33.1 \\
\hline No & 222 & 66.9 \\
\hline \multicolumn{3}{|c|}{ Indications for CS $(n=110)$} \\
\hline Obstructed labor & 31 & 28.2 \\
\hline NRFHR & 28 & 25.5 \\
\hline Previous CS & 37 & 33.6 \\
\hline Post Term & 14 & 12.7 \\
\hline
\end{tabular}

\subsection{Maternal and Newborn Outcome}

More than a half (52.7\%) of babies' Weight were between $2,500-3,999$ grams, followed by $>4,000 \mathrm{~g}$ of $39.5 \%$. Among those babies born $99.4 \%$ was alive and $48.3 \%$ have APGAR score of 4-6 and two of mothers were passed away (Table 3).

Table 3. Mothers and newborn outcome among mothers among mothers who gave a birth from January 01, 2014, to December 31, 2018, at Aira Hospital, west wollega zone, Oromia Region, Ethiopia. July 2019, $n=332$.

\begin{tabular}{lll}
\hline Obstetric History & Frequency & Percentage (\%) \\
\hline Fetal Weight & & \\
$<2500 \mathrm{G}$ & 26 & 7.8 \\
$2500-3999 \mathrm{~g}$ & 175 & 52.7 \\
$>4000 \mathrm{~g}$ & 131 & 39.5 \\
APGAR score $(\mathrm{n}=325)$ & & \\
$<3$ & 30 & 9.2 \\
$4-6$ & 157 & 48.3 \\
$>7$ & 138 & 42.4 \\
Fetal outcome $(\mathrm{n}=110)$ & & \\
Alive & 325 & 97.8 \\
Dead & 7 & 2.2 \\
Maternal outcome & & \\
Alive & 330 & 99.4 \\
Dead & 2 & 0.6 \\
\hline
\end{tabular}


Table 4. Factors associated with cesarean section among mothers who gave a birth from January 01, 2014 to December 31, 2018 at Aira Hospital, west wollega zone, Oromia Region, Ethiopia. July 2019, $n=332$.

\begin{tabular}{|c|c|c|c|c|}
\hline \multirow{2}{*}{ Characteristics } & \multicolumn{2}{|c|}{ Cesarean section } & \multirow{2}{*}{ COR 95\% CI } & \multirow{2}{*}{ AOR 95\% CI } \\
\hline & Yes n (\%) & No n (\%) & & \\
\hline \multicolumn{5}{|l|}{ Age } \\
\hline$<=24$ & $28(16.3)$ & $144(83.7)$ & 1 & 1 \\
\hline $25-34$ & $74(51.3)$ & $71(49.0)$ & $5.36(3.19,9.01)$ & $8.29(3.75,18.33)^{*}$ \\
\hline$>=35$ & $8(53.3)$ & $7(46.7)$ & $5.88(1.97,17.52)$ & $5.24(1.27,21.61)^{*}$ \\
\hline \multicolumn{5}{|l|}{ Residence } \\
\hline Urban & $43(37.7)$ & $71(62.3)$ & 1 & 1 \\
\hline Rural & $67(30.7)$ & $151(69.3)$ & $0.73(.46,1.18)$ & $1.09(0.62,1.92)$ \\
\hline \multicolumn{5}{|l|}{ Gravida } \\
\hline One & $21(23.1)$ & $70(76.8)$ & 1 & $1.04(0.43,4.51)$ \\
\hline Two-four & $67(33.5)$ & $133(66.5)$ & $1.68(0.95,2.97)$ & $0.55(0.23,1.32)$ \\
\hline Five $\&$ above & $22(53.7)$ & $19(46.3)$ & $3.86(1.72,8.45)$ & 1 \\
\hline \multicolumn{5}{|l|}{ Gestational age } \\
\hline $37-40$ weeks & $88(29.2)$ & $213(70.8)$ & 1 & 1 \\
\hline$>=40$ weeks & $22(52.9)$ & $9(47.1)$ & $5.92(2.62,13.36)$ & $4.84(2.00,11.69)^{*}$ \\
\hline \multicolumn{5}{|l|}{ Fetal Weight } \\
\hline$<2500 \mathrm{~g}$ & $12\{46.2)$ & $14(53.8)$ & 1 & 1 \\
\hline $2500-3999 g$ & $56(32.0)$ & $119(68.0)$ & $0.55(0.24,1.26)$ & $1.08(0.41,284)$ \\
\hline$>4000 \mathrm{~g}$ & $42(32.1)$ & $89(67.9)$ & $3.55(3.23,3.29)$ & $3.22(3.00,3.44)^{*}$ \\
\hline
\end{tabular}

* = significant at $\mathrm{P}<0.05, \mathrm{~g}=$ gram, $\mathrm{COR}=$ crude odd ratio, $\mathrm{AOR}$, adjusted odd ratio, $\mathrm{CI}=$ confidence interval.

Factors associated with cesarean section

Age of the mother, gestational age and infant weight were variables significantly associated with caesarean section after adjusting for other variables in multivariate logistic regression. Mothers whose age between 24-25 were eight times more likely to undergone caesarean section as compared to the mothers age of less than 24 years, with (AOR 8.29 95\% CI $(3.75,18.33)$, similarly Mothers whose age was above 35 years were five times more likely to undergone caesarean section as compared to the age less than 24 years with (AOR 5.24 95\% CI (1.27, 21.61). Mother whose gestational age was above 40 weeks were 4.8 times more likely to undergo the cesarean section as compared with those whose gestational age was between 37 - 40 week with (AOR $4.84,95 \%$ CI $(2.00,11.69))$. Those who gave birth of baby weight $>4000 \mathrm{~g}$ were 3.22 times likely undergo the cesarean section than the mother gave a birth of a baby weigh less than 200g with (AOR 3.22 95\% (3.00, 3.44) (table 4).

\section{Discussion}

This study provides information regarding the cesarean section and factors associated with it. In this study the overall prevalence of caesarean section was 33.13\% (95\%CI 31.3$35.2 \%$ ). This figure is lower when compared with the study result from middle and upper income countries like Mexico (57.3\%) [15], Iran (52.9\%) [19], Brazil (51.6\%) [26], but it is comparable with studies conducted, India (32.6\%) [27], Taiwan (31.9\%) [28], Thailand (31.5\%) [29] and Harar, Eastern Ethiopia (34.3\%) [21], On the other hand the prevalence of $\mathrm{CS}$ in this study was relatively higher compared to previous studies conducted at Mizan Aman General Hospital (21.1\%) [17] and Atata Hospital (27.6\%) southern Ethiopia [18], whereas the Ethiopian national review of cesarean rate shows $18 \%$ [12] and also higher than the finding of study conducted at St. Joseph Medical Hospital, Tanzania (18\%) [30]. But this figure is higher compared to the rate that WHO have recommended which is $15 \%$. This difference might be due to higher rates of CS in urban areas are associated with the availability of health care facilities and advanced obstetric services, high rates of maternal healthcare utilization, amongst others [20].

The major indication for caesarean section in the study was previous history of CS. This study was similar with the study conducted in Albania and Iran [31, 32]. However this finding was different from the study conducted in Felegehiwot referral hospital, Northwest Ethiopia, where the most frequent indication was obstructed labor [13]. This different might be decreased trial of spontaneous vaginal delivery and time not given for conservative management of fetal distress [26].

In this study, maternal age is significantly associated with caesarean section. An increase in the caesarean section rate with age has been reported in the majority of studies assessing this outcome [19]. Mothers in age group of 25-34 and $>35$ were 8.29 and 5.24 more likely to undergo the cesarean section respectively as compared with those women less than 24 years old. This finding is in line with the study result obtained from Nigeria, which have reported the maternal age of greater than thirty-five years, have an association with the cesarean section [33]. Other studies conducted at Japan [34] and India [23] also reported similar findings. This may be due to that those older women are more likely to experience pregnancy complication such as diabetes, hypertension and preeclampsia [17, 24].

Another factor associated with the cesarean section were gestational age. Mother whose gestational age is $>40$ weeks were more likely to undergo the cesarean section than mothers whose gestational age 37- 40 weeks. Similarly the study finding from united states of America also traces the 
cesarean delivery increases concurrently with the gestational age $[35,36]$. This may explain the high caesarean section deliveries due to postdates pregnancy; the inductions of labor may have failed or as elective CS [37].

The mother who gave birth of baby weight $>4000 \mathrm{~g}$ were 3.22 times likely undergo cesarean section than the mother gave a birth of a baby weigh less than $200 \mathrm{~g}$. This finding is supported by the study conducted in Harari town of Eastern Ethiopia [21], Nigeria [33] and Bergen, Norway [6]. Study finding from china and three American hospitals also pointed that cesarean section rate increased with the average birth weight of singleton live-birth infants [38, 39]. It is suggested that antenatal care should be strengthened and nutritional guidance during pregnancy should be paid more attention.

\section{Limitations of Study}

Since the study was based the secondary data, we were faced a challenge on the completeness and reliability of data. Use of primary data from the participants could help to assess factors including the wealth status, literacy, obesity, attitude and knowledge level concerning the cesarean section. The referral case may overestimate the real magnitude of CS. Therefore the utilization of this information for decision making should consider the limitations of this study.

\section{Conclusion}

The study revealed that the overall prevalence of caesarean section in the study area was $33.3 \%$. It is high when compared to the WHO recommended optimum upper limit of $15 \%$ prevalence. The main indication of CS was previous caesarean section. It is recommended that vaginal delivery should be encouraged in appropriate cases and the time should be given for conservative management of fetal distress rather than rushing to operation theatre with a single episode of fetal heart rate abnormality. Such effort should be taken onto consideration to keep the rate of cesarean section up to the WHO recommendation of $15 \%$. The older women should also counseled during Antenatal care to prevent cesarean section. We also recommend a future researchers to examine the attitude of service providers and their influence on the growing cesarean section delivery rate.

\section{Abbreviations}

ANC: Antenatal Care, APGAR: Appearance, Pulse, Grimace, Activity, Respiration, BSc: Bachelor of Science, CS: Cesarean Section, NRFHR: MSc: Masters of science, Non- Reassuring Fetal Heart Beat, WHO: World Health Organization, SD: Standard deviation.

\section{Ethical Approval}

Ethical clearance and study approval was obtained from Haramaya University, college of health and medical science, school of nursing and midwifery. Letter of permission was obtained from Aira hospital to access the medical records. Confidentiality was maintained by excluding personal identifiers and not sharing the data with third person.

\section{Data Availability}

The datasets used for analysis are available from the corresponding author upon reasonable request.

\section{Competing Interests}

The authors declare that there is no conflict of interest to declare for this study.

\section{Author's Contribution}

KD and GF participated in inception of idea, proposal development, data collection, analysis, and final write up. BT and HA have participated on write up of the manuscript. All authors approved the final manuscript.

\section{Acknowledgements}

We are thankful to Aira Hospital and the data collectors.

\section{References}

[1] Althabe, F. and J. M. Belizán, Caesarean section: the paradox. The Lancet, 2006. 368 (9546): p. 1472-1473.

[2] Woldeyes, W. S., D. Asefa, and G. Muleta, Incidence and determinants of severe maternal outcome in Jimma University teaching hospital, south-West Ethiopia: a prospective crosssectional study. BMC Pregnancy and Childbirth, 2018. 18 (1): p. 255.

[3] Chazotte, C. and W. R. Cohen, Catastrophic complications of previous cesarean section. American journal of obstetrics and gynecology, 1990. 163 (3): p. 738-742.

[4] Hadar, E., et al., Timing and risk factors of maternal complications of cesarean section. Archives of gynecology and obstetrics, 2011. 283 (4): p. 735-741.

[5] Yisma, E., et al., Impact of caesarean section on breastfeeding indicators: within-country and meta-analyses of nationally representative data from 33 countries in sub-Saharan Africa. BMJ Open, 2019. 9 (9): p. e027497.

[6] Häger, R. M., et al., Complications of cesarean deliveries: rates and risk factors. American journal of obstetrics and gynecology, 2004. 190 (2): p. 428-434.

[7] Organization, W. H. and UNICEF, Indicators to monitor maternal health goals: report of a technical working group. 1994

[8] Betrán, A. P., et al., The increasing trend in caesarean section rates: global, regional and national estimates: 1990-2014. PloS one, 2016.11 (2): p. e0148343.

[9] Violence, W. H. O., I. Prevention, and W. H. Organization, Global status report on road safety 2013: supporting a decade of action. 2013: World Health Organization. 
[10] Chu, K., et al., Cesarean section rates and indications in subSaharan Africa: a multi-country study from Medecins sans Frontieres. PloS one, 2012.7 (9): p. e44484.

[11] Gebremedhin, S., Trend and socio-demographic differentials of Caesarean section rate in Addis Ababa, Ethiopia: analysis based on Ethiopia demographic and health surveys data. Reproductive health, 2014. 11 (1): p. 14.

[12] Fesseha, N., et al., A national review of cesarean delivery in Ethiopia. International Journal of Gynecology \& Obstetrics, 2011. 115 (1): p. 106-111.

[13] Yisma, E., et al., Cesarean section in Ethiopia: prevalence and sociodemographic characteristics. The Journal of MaternalFetal \& Neonatal Medicine, 2019. 32 (7): p. 1130-1135.

[14] Azene, A. G., A. M. Aragaw, and M. G. Birlie, Multilevel modelling of factors associated with caesarean section in Ethiopia: community based cross sectional study. BMC Res Notes, 2019. 12 (1): p. 724.

[15] Elena, S., et al., The Epidemic of the Cesarean Section in Private Hospital in Puebla, México. Obstet Gynecol Int J, 2015. 2 (6): p. 00058.

[16] Abebe, F. E., et al., Factors leading to cesarean section delivery at Felegehiwot referral hospital, Northwest Ethiopia: a retrospective record review. Reproductive health, 2015. 13 (1): p. 6.

[17] Gutema, H. and A. Shimye, cesarean section and associated factors at mizan aman general hospital, southwest Ethiopia. J Gynecol Obstet, 2014. 2 (3): p. 37-41.

[18] Moges, A., B. Ademe, and G. Akessa, Prevalence and outcome of caesarean section in Attat Hospital, Gurage Zone, SNNPR, Ethiopia. Arch Med, 2015.7 (4): p. 1-6.

[19] REZAIE, S. B., et al., A survey on causes of cesarean sections performed at the university hospitals of Niknafs and Ali-Ibn Abi Talib of Rafsanjan, Iran, in the second trimester of 2014. 2014.

[20] Soto-Vega, E., et al., Rising Trends of Cesarean Section Worldwide: A Systematic Review. Obstet Gynecol Int J, 2015. 3 (2): p. 00073.

[21] Tsega, F., et al., Prevalence of cesarean section in urban health facilities and associated factors in Eastern Ethiopia: hospital based cross sectional study. J Preg Child Health, 2015. 2 (3): p. 169-73.

[22] Lauer, J. A., et al., Determinants of caesarean section rates in developed countries: supply, demand and opportunities for control. World health report, 2010. 29: p. 1-22.

[23] Neuman, M., et al., Prevalence and determinants of caesarean section in private and public health facilities in underserved South Asian communities: cross-sectional analysis of data from Bangladesh, India and Nepal. BMJ open, 2014. 4 (12): p. e005982.

[24] Tsegaye, H., Prevalence of Caesarean Section and Associated
Factors in Addis Ababa Hospitals, Addis Ababa, Ethiopia, 2017. 2017, Addis Ababa University.

[25] Wondie, A. G., et al., Cesarean delivery among women who gave birth in Dessie town hospitals, Northeast Ethiopia. PLoS One, 2019.14 (5): p. e0216344.

[26] Mendoza-Sassi, R. A., et al., Risk factors for cesarean section by category of health service. Revista de saúde pública, 2010. 44: p. 80-89.

[27] Sreevidya, S. and B. Sathiyasekaran, High caesarean rates in Madras (India): a population - based cross sectional study. BJOG: An International Journal of Obstetrics \& Gynaecology, 2003. 110 (2): p. 106-111.

[28] Chu, K.-H., et al., Women's preference for cesarean delivery and differences between Taiwanese women undergoing different modes of delivery. BMC health services research, 2010. 10 (1): p. 138.

[29] Chanrachakul, B., Y. Herabutya, and U. Udomsubpayakul, Epidemic of cesarean section at the general, private and university hospitals in Thailand. Journal of obstetrics and gynaecology research, 2000. 26 (5): p. 357-361.

[30] Stokke, S. J. and L. M. W. Becher, Indications for cesarean section at St. Joseph Medical Hospital, Moshi Tanzania. 2013.

[31] Azami-Aghdash, S., et al., Prevalence and causes of cesarean section in Iran: systematic review and meta-analysis. Iranian journal of public health, 2014. 43 (5): p. 545.

[32] Gjonej, R., et al., The reasons of rising trend of cesarean section rate year after year. A retrospective study. Int J Nursing and Midwifery, 2015. 7: p. 9-15.

[33] Adewuyi, E. O., et al., Cesarean delivery in Nigeria: prevalence and associated factors-a population-based crosssectional study. BMJ open, 2019.9 (6): p. e027273.

[34] Suzuki, S. and M. Nakata, Factors associated with the recent increasing cesarean delivery rate at a Japanese perinatal center. ISRN obstetrics and gynecology, 2013. 2013.

[35] Bettegowda, V. R., et al., The relationship between cesarean delivery and gestational age among US singleton births. Clinics in perinatology, 2008. 35 (2): p. 309-323.

[36] Caughey, A. B., et al., Induction of labor and cesarean delivery by gestational age. American journal of obstetrics and gynecology, 2006. 195 (3): p. 700-705.

[37] Al Busaidi, I., et al., Obstetric and non-obstetric risk factors for cesarean section in Oman. Oman medical journal, 2012. 27 (6): p. 478.

[38] Chunfeng, W., et al., Correlation between birth weight and cesarean section rate of term singleton live-birth newborns in recent 10 years. Chinese Journal of Perinatal Medicine, 2011. 14 (9): p. 530-533.

[39] Naylor, C. D., et al., Cesarean delivery in relation to birth weight and gestational glucose tolerance: pathophysiology or practice style? Jama, 1996. 275 (15): p. 1165-1170. 